\title{
Factors influencing quality of life in Moroccan postmenopausal women with osteoporotic vertebral fracture assessed by ECOS 16 questionnaire
}

\author{
Fatima E Abourazzak ${ }^{1,2}$, Fadoua Allali*1,2,3, Samira Rostom 1,2, \\ Ihsane Hmamouchi1,2, Linda Ichchou1,2, Laila El Mansouri1,2, \\ Loubna Bennani ${ }^{1,2}$, Hamza Khazzani1,2, Redouane Abouqal ${ }^{3}$ and \\ Najia Hajjaj-Hassouni ${ }^{1,2,3}$
}

\begin{abstract}
Address: ${ }^{1}$ Department of Rheumatology, El Ayachi hospital, University Hospital of Rabat-Sale, Rabat, Morocco, ${ }^{2}$ Laboratory of Information and Research on Bone Diseases (LIRPOS), Faculty of Medicine and Pharmacy, Rabat, Morocco and ${ }^{3}$ Laboratory of Biostatistics, Clinical Research and Epidemiology (LBRCE), Faculty of Medicine and Pharmacy, Rabat, Morocco
\end{abstract}

Email: Fatima E Abourazzak - f.abourazzak@yahoo.fr; Fadoua Allali* - fadouaallali@yahoo.fr; Samira Rostom - samirarostom2003@yahoo.fr; Ihsane Hmamouchi - i.hmamouchi@yahoo.fr; Linda Ichchou - ilinda19@yahoo.fr; Laila El Mansouri - la_mansouri1@yahoo.fr; Loubna Bennani - loubnabennani29@yahoo.fr; Hamza Khazzani - hamzakhazani@yahoo.fr; Redouane Abouqal - abouqal@invivo.edu; Najia Hajjaj-Hassouni - n.hajjaj@medramo.ac.ma

* Corresponding author

\section{Published: 13 March 2009}

Health and Quality of Life Outcomes 2009, 7:23 doi:10.1 186/1477-7525-7-23

This article is available from: http://www.hqlo.com/content/7///23

(c) 2009 Abourazzak et al; licensee BioMed Central Ltd.

This is an Open Access article distributed under the terms of the Creative Commons Attribution License (http://creativecommons.org/licenses/by/2.0), which permits unrestricted use, distribution, and reproduction in any medium, provided the original work is properly cited.

\begin{abstract}
Objective: The aim of the study was to evaluate factors influencing quality of life (QOL) in Moroccan postmenopausal women with osteoporotic vertebral fracture assessed by the Arabic version of ECOS 16 questionnaire.

Methods: 357 postmenopausal women were included in this study. The participants underwent bone mineral density (BMD) measurements by DXA of the lumbar spine and the total hip as well as X-ray examination of the thoraco-lumbar spine to identify subclinical vertebral fractures. Patients were asked to complete a questionnaire on clinical and sociodemographic parameters, and osteoporosis risk factors. The Arabic version of the ECOSI6 (Assessment of health related quality of life in osteoporosis questionnaire) was used to assess quality of life.

Results: The mean age was $58 \pm 7.8$ years, and the mean BMI was $28.3 \pm 4.8 \mathrm{~kg} / \mathrm{m}^{2}$. One hundred and eight women (30.1\%) were osteoporotic and $46.7 \%$ had vertebral fractures. Most were categorized as Gradel (75\%). Three independent factors were associated with a poor quality of life: low educational level $(p=0,01)$, vertebral fracture $(p=$ $0,03)$, and history of peripheral fracture $(p=0,006)$. Worse $Q O L$ was observed in the group with vertebral fracture in all domains except "pain": Physical functioning $(p=0,002)$; Fear of illness $(p=0,00 \mathrm{I})$; and Psychosocial functioning $(p=$ $0,007)$. The number of fractures was a determinant of a low $Q O L$, as indicated by an increased score in physical functioning $(p=0,0 \mathrm{I})$, fear of illness $(p=0,007)$, and total score $(p=0,0 \mathrm{I})$ after adjusting on age and educational level. Patients with higher Genant score had low $Q O L$ in these two domains too ( $p=0,002 ; p=0,001$ respectively), and in the total score $(p=0,0 I)$ after adjusting on age and educational level.
\end{abstract}

Conclusion: Our current data showed that the quality of life assessed by the Arabic version of the ECOS 16 questionnaire is decreased in post menopausal women with prevalent vertebral fractures, with the increasing number and the severity of vertebral fractures. 


\section{Background}

Osteoporosis is a growing public health concern among the elderly population, particularly in postmenopausal women. It's a debilitating chronic disease that can reduce the quality of life (QOL) in a variety of ways, including diminished physical and emotional functioning. Vertebral fractures, the hallmark of osteoporosis, are commonly associated with back pain, kyphosis, and height loss. Therefore, they can lead to a reduced mobility and may be very painful, which can limit everyday activities $[1,2]$. Reduced activities can lead to increasing isolation, which, then, negatively impacts self-esteem and selfimage, and causes depression. Studies have also shown that patients with vertebral fractures suffer from a loss of independence [3-5]. Anxiety and panic are reported early in osteoporosis [5]. All together, theses factors have an important impact on the quality of life of osteoporotic patients. Therefore, measuring the quality of life in postmenopausal women is important. Many questionnaires, either generic or disease-targeted, have been developed for the evaluation of QOL. Generic measures are applicable to various diseases, and even to the general population. Disease-targeted measures can include items that are more closely related to the disease process, and therefore can be more sensitive to the disease process when they are well designed.

Several specific questionnaires have been developed to measure QOL in osteoporosis. The most widely used are the Osteoporosis Quality of Life Questionnaire (OQLQ) $[6,7]$, the Osteoporosis Assessment Questionnaire (OPAQ) [8-11], the Osteoporosis-Targeted Quality of Life Questionnaire (OPTQOL) [5,12-14], and the Quality of Life Questionnaire of the European Foundation for Osteoporosis (QUALEFFO) [6,15-21]. However their length and administration time have limited their use to clinical trials. For this reason, specific short form questionnaires, such as the mini-OQLQ [22] and the ECOS-16 (Assessment of health-related quality of life in osteoporosis) [23], have been developed.

There is no Arabic version of ECOS-16 to evaluate QOL in Moroccan osteoporotic women. QOL depends on the cultural background of each nation. Therefore, the QOL of Moroccan osteoporotic women should be evaluated using questionnaires developed for the Moroccan population.

The aim of this study was to assess QOL in Moroccan postmenopausal women with osteoporotic vertebral fractures using a standard Arabic version of ECOS-16.

\section{Patients and methods Patients}

In this cross-sectional study, 357 ambulatory post-menopausal women living in urban areas of Morocco were sent to our outpatient Bone Densitometry Center. Recruitment was based on voluntary enrolment. All subjects were referred to this center for osteoporosis risk factors, including menopause. Informed consent was obtained from all subjects and the study was approved by ethics committee of our university hospital. We excluded from the study all patients with a history of: (1) taking drugs known to influence bone metabolism in the past 2 years, such as vitamin D, calcium, corticosteroids, bisphosphonates and hormone replacement therapy; (2) musculo skeletal, thyroid, parathyroid, adrenal, hepatic, or renal disease; (3) malignancy; and (4) hysterectomy. No adjunction or modification in treatment has been authorized.

\section{Data collection and measurements}

Each patient completed a questionnaire on clinical and sociodemographic parameters, and osteoporosis risk factors. The age of menopause, the time since menopause, educational level, personal history of peripheral fracture, back pain, and comorbid conditions were recorded.

\section{Anthropometric data}

Weight and height were measured without clothes or shoes at the time of bone densitometry measurements. The Body mass index (BMI) was calculated as body weight/height2 $(\mathrm{kg} / \mathrm{m} 2)$.

\section{Vertebral morphometry}

Lateral radiographs of the thoracic and lumbar spine were made by standard methods. Morphometry was done from T4 to L4. Vertebral fractures were diagnosed by the Genant semiquantitative method [24], a visual radiographic approach which corresponds to the attribution of grades, ranging from 0 (no vertebral fracture); 1 (20\% decrease of vertebra height); 2 (between 20 and 40\% decrease of vertebra height); to 3 (severe vertebral fracture, more than $40 \%$ decrease of vertebra height). The severity of vertebral fractures was assessed by the Genant score.

\section{Bone mineral density (BMD) measurements}

Lumbar spine, trochanter, femoral neck and total hip BMD were measured by dual-energy Xray absorptiometry with a Lunar prodigy densitometer. Daily quality control was carried out by measurement of a Lunar phantom. At the time of the study, phantom measurements showed stable results. The phantom precision expressed as the $\mathrm{CV}(\%)$ was 0.08 . Both $\mathrm{T}$ and $\mathrm{Z}$ scores were obtained. In the T-score calculations, the manufacturer's ranges for European reference population were used because of the absence of a Moroccan database. Osteoporosis was defined as a T-score lower than -2.5 , according to the World Health Organisation study group definition [25].

\section{Quality of life evaluation: ECOS-I6 Questionnaire}

The specific QOL questionnaire: ECOS-16 was used to measure QOL. The 16 items are divided qualitatively into four dimensions: Pain; Physical functioning; Fear of ill- 
ness; and Psychological functioning. ECOS-16 generates a single summary score obtained from the arithmetic mean of the answered items, so the total score ranges from 1 (best HRQOL) to 5 (worst HRQOL). The two summary scores PCS (Physical Component Summary) and MCS (Mental Component Summary) were also calculated.

The ECOS-16 questionnaire was adapted and translated into Arabic to be used in Moroccan patients with vertebral fractures. The translation followed proposed guidelines by Guillemin and et al $[26,27]$. In the first phase, the translation from the original language to the target language was done by two groups of translators. To ensure accuracy, the forward translation was back-translated into English by two other groups of translators with English culture totally blinded to the original version. The expert committee contained translators, back-translators, a sociologist, a teacher in linguistics, and two rheumatologists. Its role was to consolidate all the translated and back translated versions of the questionnaire, review the discrepancies, and develop the prefinal version of the questionnaire for field testing. A few questionable items were discussed and resolved. Globally, the adaptation did not cause any particular problems. Patients were asked to complete, the final Arabic version of ECOS-16, on 2 occasions separated by 1 week, to evaluate its reproducibility. For analphabet women, the questionnaire was read by third party without any modification of the content. Its acceptability was tested by studying the percentage of refusals, missing items, and complete questionnaires.

\section{Statistical analysis}

Statistical analysis was performed with the Windows 13.0 version of SPSS software (SPSS Inc., Chicago, IL, USA). Values are expressed as mean \pm S.D or percentages.

For the validation of the Arabic ECOS-16 questionnaire, internal consistency reliability was evaluated using Cronbach's alpha, and the test-retest reliability was evaluated by intra-class correlation coefficients (ICC) for the global score. Cronbach's alpha was calculated in each dimension of the instrument to assess the internal consistency reliability. A high alpha coefficient $(\geq 0,70)$ suggests that the items within a dimension measures the same construct and supports the construct validity [28]. The ICC estimates the correlation between two measures among the same subject. Its value is comprised between +1 (perfect reproducibility) and 0 (hopeless reproducibility). A value above 0.80 is considered usually like satisfactory [29].

Item internal convergency represents the correlation between different domains. The domain which measures similar dimensions produces high correlations. Values above 0.60 correspond to a high correlation, moderate between 0.30 and 0.60 , and low correlation below 0.30 .
For the comparison between fractured and non-fractured patients, we used Student's t-test for quantitative variables and Chi-square test for qualitative variables. A logistic regression analysis was used to discriminate between the fractured and non fractured groups and to assess risk factors of vertebral fractures. Odds ratios (OR) and 95\% confidence intervals (CI95\%) were calculated.

In order to quantify the impact of the number and the severity of vertebral fractures on QOL, multiple linear regression was performed to assess independent factors associated with a poor QOL after adjusting on potential confounding variables.

A statistical significance level of $\mathrm{p}<0.05$ was used in all statistical tests performed.

\section{Results \\ Study population}

Table 1 shows the patients' sociodemographic and clinical characteristics with a comparison between the two groups according to the presence of vertebral fractures. The mean age of patients was $58.7 \pm 7.8$ years, and the mean of BMI was $28.3 \pm 4.8$. One hundred seventy two patients $(48 \%)$ were housewives, and $68 \%$ were married. Of all participants, $27.4 \%$ were illiterate, $16 \%$ had received only primary school education, 38.7\% secondary school, and $17.9 \%$ had been to high school. Overall, $46.5 \%$ reported at least one comorbid condition. Of all women, $30.1 \%$ were osteoporotic, and $46.7 \%$ had vertebral fractures. Most of them were determined to be Grade 1 (75\%). The mean number of vertebral fractures was $2.4 \pm 1.4$. The majority was located at the thoracic level with 71 fractures (55.4\%), 4 at the lumbar level (3\%), and 51 (39.8\%) at both thoracic and lumbar spine.

\section{Psychometric proprieties of the Arabic version of ECOS-I6 questionnaire}

The questionnaire had been generally well accepted by all patients. The mean duration of administration of the Arabic version of ECOS-16 was $5.8 \pm 3.6$ minutes. It has been correctly completed by $97 \%$ of patients with no missing or confusing items.

The internal consistency was very high with a Cronbach's alpha coefficient of 0.92 among the 16 items. Test-retest reliability was analysed with an Intraclass Correlation Coefficient of 0.92 . When the different dimensions of ECOS-16 were analyzed, the internal consistency by parameter was good with a Cronbach's alpha coefficient comprised between 0.73 and 0.89 (Table 2).

All domains of ECOS 16 are correlated between themselves. The Spearman correlation coefficients are comprised between 0.328 and 0.756 . The two dimensions of 
Table I: Sociodemographic variables and clinical characteristics of menopausal women with and without vertebral fractures.

\begin{tabular}{|c|c|c|c|c|}
\hline & $\begin{array}{l}\text { All patients } \\
(n=357)\end{array}$ & With vertebral fracture $(n=128)$ & Without vertebral fracture $(n=229)$ & $\mathbf{p}$ \\
\hline Age (years) & $58.7 \pm 7.8$ & $61 \pm 8.4$ & $56.8 \pm 6.7$ & $<0.001$ \\
\hline $\begin{array}{l}\text { Age of menopause } \\
\text { (years) }\end{array}$ & $47.6 \pm 5.3$ & $46.9 \pm 5.4$ & $46.9 \pm 7.5$ & 0.89 \\
\hline $\begin{array}{l}\text { Years since menopause: } \\
\text { (years) }\end{array}$ & $10.5 \pm 9.7$ & $14.6 \pm 10$ & $7.8 \pm 8.5$ & $<0.001$ \\
\hline Marital status (\%) & & & & 0.008 \\
\hline Married & 68.1 & 60.2 & 73.6 & \\
\hline Single & 3.4 & 1.6 & 4.7 & \\
\hline Widow & 20.4 & 29.7 & 14.2 & \\
\hline Divorced & 8.1 & 8.6 & 7.4 & \\
\hline Parity & $3.7 \pm 2.4$ & $4.1 \pm 2.6$ & $3.4 \pm 2.2$ & 0.01 \\
\hline Education level (\%) & & & & 0.002 \\
\hline No formal education & 27.4 & 35.9 & 18.9 & \\
\hline Primary school & 16 & 11.7 & 23 & \\
\hline Secondary school & 38.7 & 32.8 & 43.2 & \\
\hline High school & 17.9 & 19.5 & 14.9 & \\
\hline Body mass index (\%) & & & & 0.7 \\
\hline$\leq 30$ & 66.6 & 67.2 & 64.9 & \\
\hline$>30$ & 33.4 & 32.8 & 35.1 & \\
\hline $\mathrm{N}^{\circ}$ of comorbid conditions \%) & & & & 0.11 \\
\hline None & 51.6 & 42.3 & 54 & \\
\hline $1-2$ & 44 & 50.4 & 42.4 & \\
\hline$\geq 3$ & 4.4 & 7.3 & 3.6 & \\
\hline Non-vertebral fractures (\%) & & & & 0.001 \\
\hline Presence & 12 & 19.5 & 6.1 & \\
\hline Absence & 88 & 80.5 & 93.9 & \\
\hline Back pain (\%) & & & & 0.2 \\
\hline History & 28.3 & 21.9 & 31.1 & \\
\hline Current & 60.2 & 65.6 & 59.5 & \\
\hline Absence & 11.5 & 12.5 & 9.5 & \\
\hline T-score & & & & $<0.001$ \\
\hline Normal (\%) & 27.8 & 15.9 & 33.3 & \\
\hline Osteopenie (\%) & 42.1 & 34.9 & 51.4 & \\
\hline Osteoporosis (\%) & 30.1 & 49.2 & 15.3 & \\
\hline \multicolumn{5}{|l|}{ BMD } \\
\hline Lumbar & $0.977 \pm 0.171$ & $0.905 \pm 0.175$ & $1.016 \pm 0.140$ & $<0.001$ \\
\hline Neck & $0.852 \pm 0.136$ & $0.818 \pm 0.130$ & $0.873 \pm 0.135$ & 0.001 \\
\hline Trochanter & $0.698 \pm 0.123$ & $0.655 \pm 0.119$ & $0.726 \pm 0.111$ & $<0.001$ \\
\hline Ward & $0.689 \pm 0.153$ & $0.635 \pm 0.149$ & $0.721 \pm 0.137$ & $<0.001$ \\
\hline Femoral total & $0.897 \pm 0.136$ & $0.838 \pm 0.132$ & $0.938 \pm 0.117$ & $<0.001$ \\
\hline
\end{tabular}

Continuous variables are expressed as mean \pm SD 
Table 2: Internal consistency of the Arabic version of ECOS-16 questionnaire

\begin{tabular}{ll}
\hline & Cronbach's alpha \\
\hline Pain & 0.85 \\
Physical functioning & 0.79 \\
Fear of illness & 0.73 \\
Psychosocial functioning & 0.75 \\
Physical component summary (PCS) & 0.89 \\
Mental component summary (MCS) & 0.82 \\
Total score of ECOS- 16 & 0.92 \\
\hline
\end{tabular}

the ECOS 16 correlated significantly with each other (rho $=0.675$ ) (Table 3).

\section{Risk factors of vertebral fracture}

In univariate analysis, vertebral fracture risk was significantly associated with older age $(\mathrm{p}<0.001)$, with longer duration of menopause $(\mathrm{p}<0.001)$, with higher parity ( $\mathrm{p}$ $=0.01)$, with lower educational level $(\mathrm{p}=0.002)$, with a history of peripheral fracture $(\mathrm{p}=0.001)$, and with lower $\mathrm{BMD}$ at all the sites $(\mathrm{p} \leq 0.001)$. Logistic regression showed that older age $(\mathrm{OR}=1.05, \mathrm{CI} 95 \%$ : 1.01-1.09; $\mathrm{p}=$ $0,02)$, and lower lumbar BMD (OR = 0.02, CI95\%: $0.01-$ 0.13 ; $\mathrm{p}<0,001)$ were independent factors of vertebral fracture after adjusting on age, educational level, history of peripheral fracture, and lumbar BMD.

\section{Factors associated with worse quality of life and the impact of vertebral fracture on quality of life}

Univariate analysis showed that worse HRQoL was associated to older age $(\mathrm{p}<0,001)$, higher BMI $(\mathrm{p}=0,02)$, lower educational level ( $p \leq 0,01)$, higher parity $(p=0,02)$, concomitant disease $(\mathrm{p}=0,05)$, history of peripheral fracture $(\mathrm{p}<0,001)$, and vertebral fracture $(\mathrm{p}=0,003)$.

A multivariate analysis was carried out to identify patients' characteristics that were related to the ECOS-16 score. It shows that three independent factors were associated with a poor quality of life: low educational level $(\mathrm{p}<0,05)$, vertebral fracture $(\mathrm{p}=0,03)$, and a history of peripheral fracture $(p=0,006)$ (Table 4$)$.

Patients with at least one vertebral fracture had higher ECOS-16 scores in three domains (Table 5): Physical func- tioning ( $\mathrm{p}=0,002)$; Fear of illness ( $\mathrm{p}=0,001)$; Psychosocial functioning $(\mathrm{p}=0,007)$, and in the two summary scores of ECOS-16: PCS $(p=0,01) ; \operatorname{MCS}(p=0,001)$.

\section{Impact of the number of vertebral fracture on quality of life}

Total score and all domains, except "pain", increased with increasing number of vertebral fractures in univariate analysis: Physical functioning ( $\mathrm{p}<0,001)$; Fear of illness ( $\mathrm{p}<0,001)$, psychosocial functioning $(\mathrm{p}=0,008)$, and total ECOS-16 score $(\mathrm{p}=0,001)$.

Linear regression shows that patients with higher number of fractures had worse QOL in two domains after adjusting on age and educational level: Physical functioning ( $\mathrm{p}$ $=0,01)$; Fear of illness $(\mathrm{p}=0,007)$, and total ECOS-16 score $(p=0,01)$ (Table 6$)$.

\section{Severity of vertebral fractures and quality of life}

The QOL was worse when the Genant score increased, as indicated by a higher score in different domains in univariate analysis: Physical functioning ( $\mathrm{p}<0,001)$; Fear of illness ( $p<0,001)$; Psychosocial functioning ( $p=0,009)$; total score $(\mathrm{p}=0,01)$, and in multivariate analysis after adjusting on age and educational level: Physical functioning $(\mathrm{p}=0,002)$, Fear of illness $(\mathrm{p}=0,001)$, and total score $(\mathrm{p}=0,01)$ (Table 6).

\section{Discussion}

This study shows that vertebral fractures, their number and the severity of deformities have a negative impact on QOL. Indeed, ECOS-16 scores progressively increased in patients with vertebral fractures in all dimensions, except "Pain", and in both component summary scores (PCS and MCS). QOL was impaired in patients with greater number of vertebral fractures and higher Genant score except in the domains of "pain" and "psychosocial functioning". These findings underline the validity of the Arabic version of the ECOS 16 questionnaire.

We chose and used the ECOS-16 questionnaire because it is self-administered, short, simple and easy to score. Our study showed that cross-cultural adaptation of this questionnaire maintains the psychometric properties found in the original version. This was demonstrated through the

Table 3: Correlation matrix of ECOS 16 questionnaire

\begin{tabular}{|c|c|c|c|c|c|c|c|}
\hline & Pain & Physical functioning & Fear of illness & Psychosocial functioning & PCS & MCS & Total score \\
\hline Pain & 1.000 & & & & & & \\
\hline Physical functioning & 0.738 & 1.000 & & & & & \\
\hline Fear of illness & 0.713 & 0.756 & 1.000 & & & & \\
\hline Psychosocial functioning & 0.328 & 0.520 & 0.586 & 1.000 & & & \\
\hline PCS & $0.94 I$ & 0.922 & 0.786 & 0.448 & 1.000 & & \\
\hline MCS & 0.565 & 0.704 & 0.868 & 0.910 & 0.675 & 1.000 & \\
\hline Total score & 0.824 & 0.884 & 0.897 & 0.709 & 0.913 & 0.892 & 1.000 \\
\hline
\end{tabular}

PCS = Physical Component Summary; MCS = Mental Component Summary 
Table 4: Patients' characteristics influencing total ECOS-16 score in univariate and multivariate analysis.

\begin{tabular}{|c|c|c|c|c|c|c|}
\hline & \multicolumn{3}{|c|}{ Univariate analysis } & \multicolumn{3}{|c|}{ Multivariate analysis } \\
\hline & $\beta$ & $95 \% \mathrm{Cl}$ & $p$ & $\beta$ & $95 \% \mathrm{Cl}$ & $p$ \\
\hline Age & 0.23 & 0.01 to 0.03 & 0.005 & -0.003 & -0.01 to $-0.00 \mathrm{I}$ & 0.7 \\
\hline BMI & 0.16 & 0.09 to 0.43 & 0.02 & 0.17 & 0.08 to 0.35 & 0.2 \\
\hline \multicolumn{7}{|l|}{ Marital status } \\
\hline Married & ref & & & ref & & \\
\hline Single & 0.16 & 0.04 to 0.28 & 0.7 & 0.06 & 0.02 to 0.07 & 0.3 \\
\hline Widow & 0.47 & 0.01 to 0.62 & 0.2 & 0.44 & 0.01 to 0.67 & 0.07 \\
\hline Divorced & 0.54 & 0.03 to 0.71 & 0.5 & 0.36 & 0.21 to 1.53 & 0.1 \\
\hline Parity & 0.06 & 0.003 to 0.11 & 0.02 & -0.02 & -0.35 to -0.01 & 0.5 \\
\hline \multicolumn{7}{|l|}{ Educational level } \\
\hline No formal education & ref & & & ref. & & \\
\hline Primary school & -0.74 & -1.03 to -0.45 & $<0.001$ & -0.51 & -0.82 to -0.19 & 0.03 \\
\hline Secondary school & -0.64 & -1.01 to -0.45 & 0.01 & -0.49 & -0.85 to 0.12 & 0.009 \\
\hline High school & -0.30 & -0.67 to -0.12 & 0.01 & -0.35 & -0.40 to -0.29 & 0.02 \\
\hline Comorbid condition & 0.24 & 0.01 to 0.5 & 0.05 & 0.09 & 0.03 tol. 13 & 0.5 \\
\hline History of peripheral fracture & 0.65 & 0.30 to 0.99 & $<0.001$ & 0.54 & 0.11 to 0.92 & 0.006 \\
\hline Vertebral fracture & 0.42 & 0.14 to 0.69 & 0.003 & 0.29 & 0.09 to 0.52 & 0.03 \\
\hline
\end{tabular}

Adjusting on age, BMI, marital status, parity, educational level, comorbid conditions, and history of peripheral fracture.

ref $=$ Categorical of reference

short time needed to complete the questionnaire, the low percentage of incomplete questionnaires, the high alpha coefficients for internal consistency and the good reproducibility when using the test-retest. Cronbach's alpha was $>0.70$ for the total score, the four dimensions, and the two summary scores of ECOS-16, which is in the range for internal consistency. Our results are similar to those reported in the original and Italian versions which has been validated recently for use in Italian patients $[23,30]$.

All domains and the two summary scores correlated significantly between them (rho>0.3). The Italian study showed the same results [30].

Table 5: Values of the dimensions of the ECOS- 16 in patients with and without vertebral fracture (VF)

\begin{tabular}{llll}
\hline & $\begin{array}{l}\text { With VF } \\
\text { Mean (SD) }\end{array}$ & $\begin{array}{l}\text { Without VF } \\
\text { Mean (SD) }\end{array}$ & $\mathrm{P}$ \\
\hline Pain & $2.89(1.20)$ & $2.69(1.03)$ & 0.15 \\
Physical functioning & $2.33(1.08)$ & $1.96(0.80)$ & 0.002 \\
Fear of illness & $2.39(0.96)$ & $2.04(0.72)$ & 0.001 \\
Psychosocial functioning & $2.53(1.15)$ & $2.18(0.93)$ & 0.007 \\
PCS & $2.61(1.09)$ & $2.33(0.82)$ & 0.01 \\
MCS & $2.46(0.95)$ & $2.11(0.72)$ & 0.001 \\
\hline
\end{tabular}

PCS = Physical Component Summary; MCS = Mental Component Summary
Studies showing impaired QOL in patients with vertebral fractures have been published in other countries. Adachi and al [31], representing the Canadian Multicenter Osteoporosis Study (CaMos) Research Group, reported the association of fracture with lower QOL scores. As a part of the Multiple Outcomes of Raloxifene Evaluation (MORE) study, Oleksik and al [3] reported that patients with vertebral fractures had poorer scores on the QUALEFFO than those without vertebral fractures. These authors used three measures of QOL: the Nottingham Health Profile (NHP), the EQ-5D, and the QUALEFFO. Several studies have shown that HRQol progressively deteriorates in relation to the presence and number of vertebral fractures $[32,33]$. Badia and al reported the same result in the multivariate analysis [23]. Using the Italian version of ECOS-16, the presence and the number of vertebral fractures had also a negative effect on HRQoL $(p<0.001)$ [30]. In another study using QUALEFFO, the number and higher grade of fractures were determinant of a low QOL [34].

In our study, the domain of "pain" did not show differences either between patients with and without vertebral fractures or within patients according to the number and severity of vertebral fractures. Other studies found that the pain domain was discriminant in osteoporotic women, but patients were recruited on the basis of symptoms 
Table 6: Impact of the number and the severity of vertebral fractures on QOL

\begin{tabular}{lccccc}
\hline & $\begin{array}{c}\text { Pain } \\
\beta(S E)\end{array}$ & $\begin{array}{c}\text { Physical function } \\
\beta(S E)\end{array}$ & $\begin{array}{c}\text { Fear of illness } \\
\beta(S E)\end{array}$ & $\begin{array}{c}\text { Psychosocial function } \\
\beta(S E)\end{array}$ & $\begin{array}{c}\text { Total score } \\
\beta(S E)\end{array}$ \\
\hline $\begin{array}{l}\text { Number of VF } \\
\text { Genant score }\end{array}$ & $0.04(0.07)^{*}$ & $0.15(0.06)^{* *}$ & $0.15(0.05)^{* *}$ & $0.10(0.07)^{*}$ & $0.19(0.07)^{* *}$ \\
& $0.02(0.02)^{* *}$ & $0.05(0.01)^{* *}$ & $0.05(0.01)^{* * *}$ & $0.02(0.02)^{*}$ & $0.05(0.02)^{* *}$ \\
\hline
\end{tabular}

$*_{\mathrm{p}}$ : NS(>0.05); **p $\leq 0,0$ I; ***p $\leq 0,001$

Adjusting on age and educational level

VF: Vertebral fractures

related to clinically apparent fractures and compared with patients without back pain $[21,35]$. This fact could be also explained because older fractures may be asymptomatic, or patients are already taking analgesics.

Another finding in the present study is that patient's educational level is also a determinant factor in the QOL impairment. In our study, a high level of education seems to be a protective factor against worse QOL. This finding has been reported in previous studies in patients with musculoskeletal problems [36,37], and was found in other versions of ECOS-16 [23,30]. It might be explained by the fact that women with higher levels of education tend to seek more information about their condition. This lead to better understanding of the disease and ability to cope with their condition through adherence to the prescribed medical regimen.

Our study has strengths and some limitations. The recruitment was not based on symptoms related to vertebral fractures. It had permit to evaluate the impact of old and recent, symptomatic and asymptomatic vertebral fractures on QOL. We also took into account comorbidities in the evaluation of the factors influencing the ECOS-16 score. Indeed, beside vertebral fractures, these comorbid conditions may influence QOL, especially in this elderly population. However, cross-sectional methodology did not allow us to compare the changes of QOL between patients with and without fractures. Moreover, the subjects were not recruited from the community at large, but rather, were selected from patients who underwent bone density determinations. This selection bias likely explains the relatively high prevalence of osteoporosis in the subjects studied.

\section{Conclusion}

This study has revealed that QOL in Moroccan postmenopausal women is impaired by the presence of vertebral fracture, by the increasing number and by the severity of vertebral fractures. Currently, the endpoint in the treatment of osteoporosis is considered to be the prevention of fracture, with an increase of the BMD as the surrogate endpoint. Our data indicates that the measurement of QOL is mandatory for the evaluation of osteoporotic patients. This finding will not only provide an added parameter to evaluate the effectiveness of a given program, but will also focus care providers to be more attentive to the nonmedication aspects of osteoporosis management.

\section{Competing interests}

The authors declare that they have no competing interests.

\section{Authors' contributions}

FA, NHH and RA conceived the study and supervised its design, execution, and analysis and participated in the drafting and critical review of the manuscript. FA and RA did data management and statistical analyses. All other authors enrolled patients, participated in data acquisition and critical revision of the manuscript. FEA wrote the paper with input from all investigators.

\section{Acknowledgements}

This work was supported by grants from the University Mohammed V, Souissi, Rabat-Morocco.

The University Hospital Center of Rabat-Morocco supported the bone mineral density measures.

\section{References}

I. Haczynski J, Jakimiuk A: Vertebral fractures: a hidden problem of osteoporosis. Med Sci Monit 200I, 7(5): I I08-I I I7.

2. Cook DJ, Guyatt GH, Adachi JD: Quality of life issues in women with vertebral fractures due to osteoporosis. Arthritis Rheum 1993, 36(6):2469-2475.

3. Oleksik A, Lips P, Dawson A, Minshall ME, Shen W, Cooper C, Kanis $\mathrm{J}$ : Healthrelated quality of life in postmenopausal women with low BMD with or without prevalent vertebral fractures. J Bone Miner Res 2000, I 5(7): 1384-1392.

4. Hall SE, Criddle RA, Comito TL, Prince RL: A case control study of quality of life and functional impairment in women with long standing vertebral osteoporotic fracture. Osteoporos Int 1999, 9:508-515.

5. Gold DT: The clinical impact of vertebral fractures: quality of life in women with osteoporosis. Bone 1996, 18:185S-189S.

6. Badia X, Diez-Perez A, Alvarez-Sanz C, for the Spanish Greco study group: Measuring quality of life in women with vertebral fractures due to osteoporosis: A comparison of the OQLQ and QUALEFFO. Qual Life Res 200I, 10:307-17.

7. Osteoporosis Quality of Life Study Group: Measuring quality of life in women with osteoporosis. Osteoporos Int 1997, 7:478-87.

8. Cantarelli FB, Szejnfeld VL, Oliveira LM, Ciconelli RM, Ferraz MB: Quality of life in patients with osteoporosis fractures: cultural adaptation, reliability and validity of the Osteoporosis Assessment Questionnaire. Clin Exp Rheumatol 1999, 17:547-5I.

9. Oglesby AK, Minshall ME, Shen W, Xie S, Silverman SL: The impact of incident vertebral and non-vertebral fragility fractures on health-related quality of life in established postmenopausal osteoporosis: results from the teriparatide randomized, pla- 
cebo-controlled trial in postmenopausal women. J Rheumatol 2003, 30:1579-83.

10. Crans GG, Silverman SL, Genant HK, Glass EV, Krege JH: Association of severe vertebral fractures with reduced quality of life. Reduction in the incidence of severe vertebral fractures by teriparatide. Arthritis Rheum 2004, 50:4028-34.

II. Silverman SL, Minshall ME, Shen W, Harper KD, Xie S, on behalf of the Health-Related Quality of Life Subgroup of the Multiple Outcomes of Raloxifene Evaluation Study: The relationship of healthrelated quality of life to prevalent and incident vertebral fractures in postmenopausal women with osteoporosis: results from the Multiple Outcomes of Raloxifene Evaluation Study. Arthritis Rheum 200I, 44:26II-9.

12. Lydick E, Itkin S, Zimmerman I, Yawn B, Love B, Kleerekoper M, Ross $P$, Martin A, Holmes R: Development and validation of a discriminative quality of life questionnaire for osteoporosis (the OPTQoL). J Bone Min Res 1997, 1 2:456-73.

13. Martin AR, Sornay-Rendu E, Chandler JM, Duboeuf F, Girman CJ, Delmas PD: The impact of osteoporosis on quality-oflife: the OFELY cohort. Bone 2002, 31:32-6.

14. Chandler JM, Martin AR, Girman C, Ross PD, Love-McClung B, Lydick E, Yawn BP: Reliability of an osteoporosis-targeted quality of life survey instrument for use in the community: OPTQoL. Osteoporos Int 1998, 8:127-35

15. Oleksik A, Lips P, Dawson A, Minshall ME, Shen W, Cooper C, Kanis $\mathrm{J}$ : Healthrelated quality of life in postmenopausal women with low BMD with or without prevalent vertebral fractures. J Bone Miner Res 2000, 15: 1384-92.

16. Koçyigit $\mathrm{H}$, Gulseren S, Erol A, Hizli N: The reliability and validity of the Turkish version of quality of life questionnaire of the European Foundation for Osteoporosis (QUALEFFO). Clin Rheumatol 2003, 22: 18-23.

17. Oleksik AM, Ewing S, Shen W, Van Schoor NM, Lips P: Impact of incident vertebral fractures on health related quality of life (HRQOL) in postmenopausal women with prevalent vertebral fractures. Osteoporos Int 2005, 16:86I-70.

18. Romagnoli E, Carnevale V, Nofroni I, D'Erasmo E, Paglia F, De Geronimo S, Pepe J, Raejntroph N, Maranghi M, Minisola S: Quality of life in ambulatory postmenopausal women: the impact of reduced bone mineral density and subclinical vertebral fractures. Osteoporos Int 2004, 15:975-80.

19. Lips P, Cooper C, Agnusdei D, Caulin F, Egger P, Johnell O, Kanis JA, Kellingray S, Leplege A, Liberman UA, McCloskey E, Minne H, Reeve J, Reginster JY, Scholz M, Todd C, de Vernejoul MC, Wiklund I: Quality of life in patients with vertebral fractures: validation of the Quality of Life Questionnaire of the European Foundation for Osteoporosis (QUALEFFO). Working Party for Quality of Life of the European Foundation for Osteoporosis. Osteoporos Int 1999, 10:150-60.

20. Murrell P, Todd CJ, Martin A, Walton J, Lips P, Reeve J, on behalf of the Working Party for Quality of Life of the International Osteoporosis Foundation: Postal administration compared with nursesupported administration of the QUALEFFO-4I in a population sample: comparison of results and assessment of psychometric properties. Osteoporos Int 200I, I 2:672-9.

21. Cook DJ, Guyatt GH, Adachi JD, Clifton J, Griffith LE, Epstein RS, Juniper EF: Quality of life issues in women with vertebral fractures due to osteoporosis. Arthritis Rheum 1993, 36:750-6.

22. Cook DJ, Guyatt GH, Adachi JD, Epstein RS, Juniper EF: Development and validation of the mini-Osteoporosis Quality of Life Questionnaire (OQLQ) in osteoporosis women with back pain due to vertebral fractures. Osteoporosis quality of life study group. Osteoporos Int 1999, 10:207-13.

23. Badia X, Diez-Perez A, Lahoz R, Lizan L, Nogues X, lborra J: The ECOS- 16 questionnaire for the evaluation of health related quality of life in postmenopausal women with osteoporosis. Health Qual Life Outcomes 2004, 2:4I.

24. Genant HK, Wu CY, Van Kuijk C, Nevitt MC: Vertebral fracture assessment using a semiquantitative technique. J Bone Miner Res 1993, 8(9): | |37-| | 48.

25. Worls Health Organisation Study Group: Assessment of fracture risk and its application to screening for post-menopausal osteoporosis. In WHO Technical Report Series, No.843 WHO, Geneva; 1994.
26. Guillemin F, Bombardier C, Beaton D: Cross-cultural adaptation of health-related quality of life measures: literature revue and proposed guidelines. J Clin Epidemiol 1993, 46:1417-32.

27. Beaton D, Bombardier C, Guillemin F, Ferraz MB: Guidelines for the process of cross-cultural adaptation of self-report measures. Spine 2000, 25:3|86-9|

28. Cronbach LJ: Coefficient alpha and the internal structure of tests. Psychometrika 195I, 16:297-334.

29. Leplège $A$, Coste J: Mesure de la santé perceptuelle et de la qualité de vie: méthodes et applications. Paris: Estem; 200I.

30. Salaffi F, Malavolta N, Cimmino MA, Di Matteo L, Scendoni P, Carotti M, Stancati A, Mulé R, Frigato M, Gutierrez M, Grassi W, Italian Multicentre Osteoporotic Fracture (IMOF) Study Group: Validity and reliability of the Italian version of the ECOS-16 questionnaire in post-menopausal women with prevalent vertebral fractures due to osteoporosis. Clin Exp Rheumatol 2007, 25:390-403.

31. Adachi JD, Loannidis G, Berger C, Joseph L, Papaioannou A, Pickard L, Papadimitropoulos EA, Hopman W, Poliquin S, Prior JC, Hanley DA, Olszynski WP, Anastassiades T, Brown JP, Murray T, Jackson SA, Tenenhouse A, Canadian Multicentre Osteoporosis Study (CaMos) Research Group: The influence of osteoporotic fractures on health-related quality of life in community-dwelling men and women across Canada. Osteoporos Int 200I, I 2:903-908.

32. Burger H, van Daele PLA, Grashuis K, Hofman A, Grobbee DE, Schütte HE, Birkenhäger JC, Pols HA: Vertebral deformities and functional impairment in men and women. J Bone Miner Res 1997, 12:152-157.

33. Silverman SL: The Osteoporosis Assessment Questionnaire (OPAQ): A reliable and valid disease-targeted measure of health-related quality of life in osteoporosis. Qual Life Res 2000 , 9:764-774.

34. Fechtenbaum J, Cropet C, Kolta S, Horlait S, Orcel P, Roux C: The severity of vertebral fractures and health-related quality of life in osteoporotic post menopausal women. Osteoporos Int 2005, 16:2175-2179.

35. Lips $\mathrm{P}$, Cooper C, Agnusdei D, Caulin F, Egger P, Johnell O, Kanis JA Liberman U, Minne H, Reeve J, Reginster JY, de Vernejoul MC, Wiklund I: Quality of life as outcome in the treatment of osteoporosis: the development of a questionnaire for quality of life by the European Foundation for Osteoporosis. Osteoporos Int 1997, 7:36-38.

36. Creamer P, Lethbridge-Cejku M, Hochberg MC: Determinants of pain severity in knee osteoarthritis: effect of demographic and psychosocial variables using 3 pain measures. J Rheumatol 1999, 26: 1785-I792.

37. Taft LB, Looker PA, Cella D: Osteoporosis: a disease management opportunity. Orthop Nurs 2000, 19:67-76.

\begin{tabular}{|l|}
\hline Publish with Bio Med Central and every \\
scientist can read your work free of charge \\
"BioMed Central will be the most significant development for \\
disseminating the results of biomedical research in our lifetime. " \\
Sir Paul Nurse, Cancer Research UK \\
Your research papers will be: \\
• available free of charge to the entire biomedical community \\
• peer reviewed and published immediately upon acceptance \\
• cited in PubMed and archived on PubMed Central \\
• yours - you keep the copyright \\
Submit your manuscript here: \\
http://www.biomedcentral.com/info/publishing_adv.asp
\end{tabular}

